\title{
A strong convergence theorem for fixed points of generalized asymptotically quasi- $\phi$-nonexpansive mappings
}

Juan Zhao ${ }^{1}$ and Tieguo $\mathrm{Ji}^{2 *}$

\begin{abstract}
The purpose of this paper is to investigate a hybrid projection algorithm for a pair of generalized asymptotically quasi- $\phi$-nonexpansive mappings. Strong convergence of the purposed algorithm is obtained in a uniformly smooth and uniformly convex Banach space.

MSC: 47H09; 47J25

Keywords: generalized asymptotically quasi- $\phi$-nonexpansive mapping; relatively nonexpansive mapping; generalized projection; fixed point
\end{abstract}

\section{Introduction}

The theory of iterative algorithms is a popular research topic of common interest in two areas of nonlinear analysis and optimization. Applications of iterative algorithms are found in a wide range of areas, including economics, image recovery, optimization, signal processing and a lot of real world applications; see [1-22] and the references therein. Many well-known problems can be studied by using algorithms which are iterative in their nature. As an example, in computer tomography with limited data, each piece of information implies the existence of a convex set $C_{m}$ in which the required solution lies. The problem of finding a point in the intersection $\bigcap_{m=1}^{N} C_{m}$, where $N \geq 1$ is some positive integer, is then of crucial interest, and it cannot be usually solved directly. Therefore, an iterative algorithm must be used to approximate such a point.

The purpose of this paper is to investigate a hybrid projection algorithm for a pair of generalized asymptotically quasi- $\phi$-nonexpansive mappings. The organization of this paper is as follows. In Section 2, we provide some necessary preliminaries. In Section 3, a modified Halpern iterative algorithm is investigated. Strong convergence of the purposed algorithm is obtained in a uniformly convex and uniformly smooth Banach space. Some subresults are also deduced.

\section{Preliminaries}

Let $E$ be a real Banach space, $C$ be a nonempty subset of $E$ and $T: C \rightarrow C$ be a nonlinear mapping. The mapping $T$ is said to be asymptotically regular on $C$ if for any bounded

C2013 Zhao and Ji; licensee Springer. This is an Open Access article distributed under the terms of the Creative Commons Attribution License (http://creativecommons.org/licenses/by/2.0), which permits unrestricted use, distribution, and reproduction in any medium, provided the original work is properly cited. 
subset $K$ of $C$,

$$
\limsup _{n \rightarrow \infty}\left\{\left\|T^{n+1} x-T^{n} x\right\|: x \in K\right\}=0 .
$$

The mapping $T$ is said to be closed if for any sequence $\left\{x_{n}\right\} \subset C$ such that $\lim _{n \rightarrow \infty} x_{n}=x_{0}$ and $\lim _{n \rightarrow \infty} T x_{n}=y_{0}$, then $T x_{0}=y_{0}$. A point $x \in C$ is a fixed point of $T$ provided $T x=x$. In this paper, we use $F(T)$ to denote the fixed point set of $T$ and use $\rightarrow$ and $\rightarrow$ to denote the strong convergence and weak convergence, respectively.

Recall that the mapping $T$ is said to be nonexpansive if

$$
\|T x-T y\| \leq\|x-y\|, \quad \forall x, y \in C .
$$

$T$ is said to be asymptotically nonexpansive if there exists a sequence $\left\{k_{n}\right\} \subset[1, \infty)$ with $k_{n} \rightarrow 1$ as $n \rightarrow \infty$ such that

$$
\left\|T^{n} x-T^{n} y\right\| \leq k_{n}\|x-y\|, \quad \forall x, y \in C, \forall n \geq 1 .
$$

The class of asymptotically nonexpansive mappings was introduced by Goebel and Kirk [23] in 1972. In uniformly convex Banach spaces, they proved that if $C$ is nonempty bounded closed and convex, then every asymptotically nonexpansive self-mapping $T$ on $C$ has a fixed point. Further, the fixed point set of $T$ is closed and convex. Since 1972, a host of authors have studied the weak and strong convergence of iterative algorithms for such a class of mappings.

One of classical iterations is the Halpern iteration [24] which generates a sequence in the following manner:

$$
\forall x_{1} \in C, \quad x_{n+1}=\alpha_{n} u+\left(1-\alpha_{n}\right) T x_{n}, \quad \forall n \geq 1,
$$

where $\left\{\alpha_{n}\right\}$ is a sequence in the interval $(0,1)$ and $u \in C$ is a fixed element.

Since 1967, the Halpern iteration has been studied extensively by many authors; see, for example, [25-31]. It is well known that the following two restrictions

(C1) $\lim _{n \rightarrow \infty} \alpha_{n}=0$;

(C2) $\sum_{n=1}^{\infty} \alpha_{n}=\infty$

are necessary if the Halpern iterative sequence is strongly convergent for all nonexpansive self-mappings defined on $C$. To improve the rate of convergence of the Halpern iterative sequence, we cannot rely only on the iteration itself. Hybrid projection methods recently have been applied to solve the problem.

Martinez-Yanes and $\mathrm{Xu}$ [27] considered the hybrid projection algorithm for a single nonexpansive mapping in a Hilbert space. Strong convergence theorems are established under condition (C1) only imposed on the control sequence. To be more precise, they proved the following theorem.

Theorem 2.1 Let $H$ be a real Hilbert space, $C$ be a closed convex subset of $H$ and $T: C \rightarrow$ $C$ be a nonexpansive mapping such that $F(T) \neq \emptyset$. Assume that $\left\{\alpha_{n}\right\} \subset(0,1)$ is such that 
$\lim _{n \rightarrow \infty} \alpha_{n}=0$. Then the sequence $\left\{x_{n}\right\}$ defined by

$$
\left\{\begin{array}{l}
x_{0} \in C \quad \text { chosen arbitrarily, } \\
y_{n}=\alpha_{n} x_{0}+\left(1-\alpha_{n}\right) T x_{n} \\
C_{n}=\left\{z \in C:\left\|y_{n}-z\right\|^{2} \leq\left\|x_{n}-z\right\|^{2}+\alpha_{n}\left(\left\|x_{0}\right\|^{2}+2\left\langle x_{n}-x_{0}, z\right\rangle\right)\right\} \\
Q_{n}=\left\{z \in C:\left\langle x_{0}-x_{n}, x_{n}-z\right\rangle \geq 0\right\} \\
x_{n+1}=P_{C_{n} \cap Q_{n}} x_{0}, \quad \forall n \geq 0
\end{array}\right.
$$

converges strongly to $P_{F(T)} x_{0}$.

Recently, some authors considered the problem of extending Theorem MYX to a Banach space. In this paper, we consider, in the framework of Banach spaces, the problem of modifying the Halpern iteration by hybrid projection algorithms such that strong convergence is available under assumption $(\mathrm{C} 1)$ only. Before proceeding further, we give some definitions and propositions in Banach spaces first.

Let $E$ be a Banach space with the dual $E^{*}$. We denote by $J$ the normalized duality mapping from $E$ to $2^{E^{*}}$ defined by

$$
J x=\left\{f^{*} \in E^{*}:\left\langle x, f^{*}\right\rangle=\|x\|^{2}=\left\|f^{*}\right\|^{2}\right\},
$$

where $\langle\cdot, \cdot\rangle$ denotes the generalized duality pairing.

A Banach space $E$ is said to be strictly convex if $\left\|\frac{x+y}{2}\right\|<1$ for all $x, y \in E$ with $\|x\|=\|y\|=1$ and $x \neq y$. It is said to be uniformly convex if $\lim _{n \rightarrow \infty}\left\|x_{n}-y_{n}\right\|=0$ for any two sequences $\left\{x_{n}\right\}$ and $\left\{y_{n}\right\}$ in $E$ such that $\left\|x_{n}\right\|=\left\|y_{n}\right\|=1$ and $\lim _{n \rightarrow \infty}\left\|\frac{x_{n}+y_{n}}{2}\right\|=1$. Let $U_{E}=\{x \in E:\|x\|=$ 1 ) be the unit sphere of $E$. Then the Banach space $E$ is said to be smooth provided

$$
\lim _{t \rightarrow 0} \frac{\|x+t y\|-\|x\|}{t}
$$

exists for each $x, y \in U_{E}$. It is also said to be uniformly smooth if the limit (2.3) is attained uniformly for $x, y \in U_{E}$. It is well known that if $E$ is uniformly smooth, then $J$ is uniformly norm-to-norm continuous on each bounded subset of $E$. It is also well known that $E$ is uniformly smooth if and only if $E^{*}$ is uniformly convex.

Recall that a Banach space $E$ enjoys the Kadec-Klee property if for any sequence $\left\{x_{n}\right\} \subset E$, and $x \in E$ with $x_{n} \rightarrow x$, and $\left\|x_{n}\right\| \rightarrow\|x\|$, then $\left\|x_{n}-x\right\| \rightarrow 0$ as $n \rightarrow \infty$. For more details on the Kadec-Klee property, the readers can refer to [32] and the references therein. It is well known that if $E$ is a uniformly convex Banach space, then $E$ enjoys the Kadec-Klee property.

As we all know, if $C$ is a nonempty closed convex subset of a Hilbert space $H$ and $P_{C}: H \rightarrow C$ is the metric projection of $H$ onto $C$, then $P_{C}$ is nonexpansive. This fact actually characterizes Hilbert spaces and, consequently, it is not available in more general Banach spaces. In this connection, Alber [33] recently introduced a generalized projection operator $\Pi_{C}$ in a Banach space $E$ which is an analogue of the metric projection in Hilbert spaces.

Next, we assume that $E$ is a smooth Banach space. Consider the functional defined by

$$
\phi(x, y)=\|x\|^{2}-2\langle x, J y\rangle+\|y\|^{2} \quad \text { for } x, y \in E .
$$


Observe that, in a Hilbert space $H,(2.4)$ is reduced to $\phi(x, y)=\|x-y\|^{2}, x, y \in H$. The generalized projection $\Pi_{C}: E \rightarrow C$ is a map that assigns to an arbitrary point $x \in E$ the minimum point of the functional $\phi(x, y)$, that is, $\Pi_{C} x=\bar{x}$, where $\bar{x}$ is the solution to the minimization problem

$$
\phi(\bar{x}, x)=\min _{y \in C} \phi(y, x) .
$$

Existence and uniqueness of the operator $\Pi_{C}$ follows from the properties of the functional $\phi(x, y)$ and strict monotonicity of the mapping $J$; see, for example, [32]. In Hilbert spaces, $\Pi_{C}=P_{C}$. It is obvious from the definition of a function $\phi$ that

$$
\begin{aligned}
& (\|x\|-\|y\|)^{2} \leq \phi(x, y) \leq(\|y\|+\|x\|)^{2}, \quad \forall x, y \in E, \\
& \phi(x, y)=\phi(x, z)+\phi(z, y)+2\langle x-z, J z-J y\rangle, \quad \forall x, y, z \in E .
\end{aligned}
$$

Remark 2.2 If $E$ is a reflexive, strictly convex and smooth Banach space, then for $x, y \in E$, $\phi(x, y)=0$ if and only if $x=y$. It is sufficient to show that if $\phi(x, y)=0$, then $x=y$. From (2.5), we have $\|x\|=\|y\|$. This implies that $\langle x, J y\rangle=\|x\|^{2}=\|J y\|^{2}$. From the definition of $J$, we have $J x=J y$. Therefore, we have $x=y$; for more details, see [32] and the references therein.

Let $C$ be a nonempty closed convex subset of $E$ and $T$ be a mapping from $C$ into itself. A point $p$ in $C$ is said to be an asymptotic fixed point of $T$ if $C$ contains a sequence $\left\{x_{n}\right\}$ which converges weakly to $p$ such that $\lim _{n \rightarrow \infty}\left\|x_{n}-T x_{n}\right\|=0$. The set of asymptotic fixed points of $T$ will be denoted by $\widetilde{F}(T)$. A mapping $T$ from $C$ into itself is said to be relatively nonexpansive if $\widetilde{F}(T)=F(T) \neq \emptyset$ and $\phi(p, T x) \leq \phi(p, x)$ for all $x \in C$ and $p \in F(T)$. The mapping $T$ is said to be relatively asymptotically nonexpansive [34] if $\widetilde{F}(T)=F(T) \neq \emptyset$ and there exists a sequence $\left\{k_{n}\right\} \subset[1, \infty)$ with $k_{n} \rightarrow 1$ as $n \rightarrow \infty$ such that $\phi(p, T x) \leq k_{n} \phi(p, x)$ for all $x \in C, p \in F(T)$ and $n \geq 1$.

The mapping $T$ is said to be quasi- $\phi$-nonexpansive [35] if $F(T) \neq \emptyset$ and $\phi(p, T x) \leq \phi(p, x)$ for all $x \in C$ and $p \in F(T) . T$ is said to be asymptotically quasi- $\phi$-nonexpansive [36] and [37] if $F(T) \neq \emptyset$ and there exists a sequence $\left\{k_{n}\right\} \subset[0, \infty)$ with $k_{n} \rightarrow 1$ as $n \rightarrow \infty$ such that $\phi(p, T x) \leq k_{n} \phi(p, x)$ for all $x \in C, p \in F(T)$ and $n \geq 1$.

Remark 2.3 The class of asymptotically quasi- $\phi$-nonexpansive mappings is more general than the class of relatively asymptotically nonexpansive mappings which requires the restriction $F(T)=\widetilde{F}(T)$.

Recently, Qin et al. [29] further improved the above results by considering the so-called shrinking projection method for a quasi- $\phi$-nonexpansive mapping. To be more precise, they proved the following theorem.

Theorem 2.4 Let $C$ be a nonempty closed and convex subset of a uniformly convex and uniformly smooth Banach space E, and let $T: C \rightarrow C$ be a closed and quasi- $\phi$ nonexpansive mapping such that $F(T) \neq \emptyset$. Let $\left\{x_{n}\right\}$ be a sequence generated in the following 
manner:

$$
\left\{\begin{array}{l}
x_{0} \in E \quad \text { chosen arbitrarily, } \\
C_{1}=C \\
x_{1}=\Pi_{C_{1}} x_{0} \\
y_{n}=J^{-1}\left[\alpha_{n} J x_{1}+\left(1-\alpha_{n}\right) J T x_{n}\right] \\
C_{n+1}=\left\{z \in C_{n}: \phi\left(z, y_{n}\right) \leq \alpha_{n} \phi\left(z, x_{0}\right)+\left(1-\alpha_{n}\right) \phi\left(z, x_{n}\right)\right\} \\
x_{n+1}=\Pi_{C_{n+1}} x_{1} .
\end{array}\right.
$$

Assume that the control sequence satisfies the restriction $\lim _{n \rightarrow \infty} \alpha_{n}=0$. Then $\left\{x_{n}\right\}$ converges strongly to $\Pi_{F(T)} x_{1}$.

Recently, Qin et al. [38] introduced a class of generalized asymptotically quasi- $\phi$ nonexpansive mappings. Recall that a mapping $T$ is said to be generalized asymptotically quasi- $\phi$-nonexpansive if $F(T) \neq \emptyset$ and there exist a sequence $\left\{\mu_{n}\right\} \subset[1, \infty)$ with $\mu_{n} \rightarrow 1$ as $n \rightarrow \infty$ and a sequence $\left\{v_{n}\right\} \subset[0, \infty)$ with $v_{n} \rightarrow 0$ as $n \rightarrow \infty$ such that $\phi(p, T x) \leq \mu_{n} \phi(p, x)+v_{n}$ for all $x \in C, p \in F(T)$ and $n \geq 1$.

In $E$ is a Hilbert space, the mapping $T$ is reduced to a generalized asymptotically quasinonexpansive mapping, which was considered by Agarwal et al. [39], Shahzad and Zegeye [40] and Lan [41]. Next, we give examples of the mapping.

Let $E=\mathbb{R}^{1}$ and $C=[0,1]$. Define the following mapping $T: C \rightarrow C$ by

$$
T x= \begin{cases}\frac{1}{2} x, & x \in\left[0, \frac{1}{2}\right], \\ 0, & x \in\left(\frac{1}{2}, 1\right] .\end{cases}
$$

Then $T$ is a generalized asymptotically $\phi$-nonexpansive mapping with the fixed point set $\{0\}$. We also have the following

$$
\begin{aligned}
& \phi\left(T^{n} x, T^{n} y\right)=\left|T^{n} x-T^{n} y\right|^{2}=\frac{1}{2^{2 n}}|x-y|^{2} \leq|x-y|^{2}=\phi(x, y), \quad \forall x, y \in\left[0, \frac{1}{2}\right], \\
& \phi\left(T^{n} x, T^{n} y\right)=\left|T^{n} x-T^{n} y\right|^{2}=0 \leq|x-y|^{2}=\phi(x, y), \quad \forall x, y \in\left(\frac{1}{2}, 1\right]
\end{aligned}
$$

and

$$
\begin{aligned}
\phi\left(T^{n} x, T^{n} y\right) & =\left|T^{n} x-T^{n} y\right|^{2} \\
& =\left|\frac{1}{2^{n}} x-0\right|^{2} \\
& \leq\left(\frac{1}{2^{n}}|x-y|+\frac{1}{2^{n}}|y|\right)^{2} \\
& \leq\left(|x-y|+\frac{1}{2^{n}}\right)^{2} \\
& \leq|x-y|^{2}+\xi_{n} \\
& =\phi(x, y)+\xi_{n}, \quad \forall x \in\left[0, \frac{1}{2}\right], \forall y \in\left(\frac{1}{2}, 1\right],
\end{aligned}
$$


where $\xi_{n}=\frac{1}{2^{2 n}}+\frac{1}{2^{n-1}}$. Hence, we have

$$
\phi\left(T^{n} x, T^{n} y\right) \leq \phi(x, y)+\xi_{n}, \quad \forall x, y \in[0,1] .
$$

This shows that $T$ a generalized asymptotically $\phi$-nonexpansive mapping instead of an asymptotically $\phi$-nonexpansive mapping.

Let $E=l^{2}$ with the norm $\|\cdot\|$ defined by $\|x\|=\sqrt{\sum_{i=1}^{\infty} x_{i}^{2}}$ and

$$
C=\left\{x=\left(x_{1}, x_{2}, \ldots, x_{n}, \ldots\right) \mid x_{1} \leq 0, x_{i} \in \mathbb{R}, i=2,3, \ldots\right\} .
$$

Define $T: C \rightarrow C$ by

$$
T x=\left(0,4 x_{1}, 0, \ldots\right), \quad \forall x \in C .
$$

Then $T$ is generalized asymptotically quasi- $\phi$-nonexpansive but not asymptotically quasi$\phi$-nonexpansive; for more details, see Lan [41] and the references therein.

In this paper, motivated by the above results, we investigate a hybrid projection algorithm for a pair of generalized asymptotically quasi- $\phi$-nonexpansive mappings. Strong convergence of the purposed algorithm is obtained in a uniformly convex and smooth Banach space. The results presented in this paper mainly improve the corresponding results in Wu and Hao [25], Cho et al. [26], Martinez-Yanes and Xu [27], Plubtieng and Ungchittrakool [28], Qin et al. [29] and Qin and Su [31].

In order to give our main results, we need the following lemmas.

Lemma 2.5 [33] Let $C$ be a nonempty closed convex subset of a smooth Banach space $E$ and $x \in E$. Then $x_{0}=\Pi_{C} x$ if and only if

$$
\left\langle x_{0}-y, J x-J x_{0}\right\rangle \geq 0, \quad \forall y \in C
$$

Lemma 2.6 [33] Let E be a reflexive, strictly convex and smooth Banach space, $C$ be a nonempty closed convex subset of $E$ and $x \in E$. Then

$$
\phi\left(y, \Pi_{C} x\right)+\phi\left(\Pi_{C} x, x\right) \leq \phi(y, x), \quad \forall y \in C .
$$

Lemma 2.7 [42] Let E be a uniformly convex Banach space and $B_{r}(0)$ be a closed ball of $X$. Then there exists a continuous strictly increasing convex function $g:[0, \infty) \rightarrow[0, \infty)$ with $g(0)=0$ such that

$$
\|\lambda x+\mu y+\gamma z\|^{2} \leq \lambda\|x\|^{2}+\mu\|y\|^{2}+\gamma\|z\|^{2}-\lambda \mu g(\|x-y\|)
$$

for all $x, y, z \in B_{r}(0)$ and $\lambda, \mu, \gamma \in[0,1]$ with $\lambda+\mu+\gamma=1$.

Lemma 2.8 [43] Let E be a uniformly convex and smooth Banach space, and let $\left\{x_{n}\right\}$ and $\left\{y_{n}\right\}$ be two sequences of E. If $\phi\left(x_{n}, y_{n}\right) \rightarrow 0$ and either $\left\{x_{n}\right\}$ or $\left\{y_{n}\right\}$ is bounded, then $x_{n}-y_{n} \rightarrow 0$. 


\section{Main results}

Theorem 3.1 Let E be a uniformly convex and uniformly smooth Banach space. Let C be a nonempty closed and convex subset of $E$. Let $T: C \rightarrow C$ be a closed and generalized asymptotically quasi- $\phi$-nonexpansive mapping with a sequence $\left\{e_{n}\right\} \subset[1, \infty)$ such that $e_{n} \rightarrow 1$ as $n \rightarrow \infty$ and a sequence $\left\{\mu_{n}\right\} \subset[0, \infty)$, where $v_{n} \rightarrow 0$ as $n \rightarrow \infty$. Let $S: C \rightarrow C$ be a closed and generalized asymptotically quasi- $\phi$-nonexpansive mapping with a sequence $\left\{f_{n}\right\} \subset[1, \infty)$ such that $f_{n} \rightarrow 1$ as $n \rightarrow \infty$ and a sequence $\left\{v_{n}\right\} \subset[0, \infty)$, where $v_{n} \rightarrow 0$ as $n \rightarrow \infty$. Assume that $T$ and $S$ are asymptotically regular on $C$ and $\mathcal{F}=F(T) \cap F(S)$ is nonempty and bounded. Let $\left\{x_{n}\right\}$ be a sequence generated in the following manner:

$$
\left\{\begin{array}{l}
x_{0} \in E \quad \text { chosen arbitrarily, } \\
C_{1}=C \\
x_{1}=\Pi_{C_{1} x_{0}} \\
z_{n}=J^{-1}\left(\beta_{n} J x_{n}+\gamma_{n} J T^{n} x_{n}+\delta_{n} J S^{n} x_{n}\right), \\
y_{n}=J^{-1}\left(\alpha_{n} J x_{1}+\left(1-\alpha_{n}\right) J z_{n}\right), \\
C_{n+1}=\left\{z \in C_{n}: \phi\left(z, y_{n}\right) \leq \phi\left(z, x_{n}\right)+\alpha_{n}\left(\left\|x_{1}\right\|^{2}+2\left\langle z, J x_{n}-J x_{1}\right\rangle\right)+\left(k_{n}-1\right) M_{n}+\xi_{n}\right\} \\
x_{n+1}=\Pi_{C_{n+1}} x_{1},
\end{array}\right.
$$

where $k_{n}=\max \left\{e_{n}, f_{n}\right\}, \xi_{n}=\max \left\{\mu_{n}, v_{n}\right\}, M_{n}=\sup \left\{\phi\left(z, x_{n}\right): z \in \mathcal{F}\right\}$ for each $n \geq 1$ and $\left\{\alpha_{n}\right\}$, $\left\{\beta_{n}\right\},\left\{\gamma_{n}\right\}$ and $\left\{\delta_{n}\right\}$ are real sequences in $(0,1)$ such that

(a) $\beta_{n}+\gamma_{n}+\delta_{n}=1$

(b) $\lim _{n \rightarrow \infty} \alpha_{n}=\lim _{n \rightarrow \infty} \beta_{n}=0$;

(c) $\liminf _{n \rightarrow \infty} \gamma_{n} \delta_{n}>0$.

Then the sequence $\left\{x_{n}\right\}$ converges strongly to $\Pi_{\mathcal{F}} x_{1}$, where $\Pi_{\mathcal{F}}$ is the generalized projection from $C$ onto $\mathcal{F}$.

Proof First, we show that $\mathcal{F}$ is closed and convex. Since $T$ and $S$ are closed, we can easily conclude that $F(T)$ and $F(S)$ are also closed. This proves that $\mathcal{F}$ is closed. Next, we prove the convexity of $\mathcal{F}$. Let $p_{1}, p_{2} \in F(T)$, and $p=t p_{1}+(1-t) p_{2}$, where $t \in(0,1)$. We see that $p=T p$. Indeed, we see from the definition of $T$ that

$$
\phi\left(p_{1}, T^{n} p\right) \leq k_{n} \phi\left(p_{1}, p\right)+\xi_{n}
$$

and

$$
\phi\left(p_{2}, T^{n} p\right) \leq k_{n} \phi\left(p_{2}, p\right)+\xi_{n} .
$$

In view of (2.6), we obtain that

$$
\phi\left(p_{1}, T^{n} p\right)=\phi\left(p_{1}, p\right)+\phi\left(p, T^{n} p\right)+2\left\langle p_{1}-p, J p-J T^{n} p\right\rangle
$$

and

$$
\phi\left(p_{1}, T^{n} p\right)=\phi\left(p_{1}, p\right)+\phi\left(p, T^{n} p\right)+2\left\langle p_{1}-p, J p-J T^{n} p\right\rangle .
$$


Combining (3.1), (3.2), (3.3) with (3.4) yields that

$$
\phi\left(p, T^{n} p\right) \leq\left(k_{n}-1\right) \phi\left(p_{1}, p\right)+2\left\langle p-p_{1}, J p-J T^{n} p\right\rangle+\xi_{n}
$$

and

$$
\phi\left(p, T^{n} p\right) \leq\left(k_{n}-1\right) \phi\left(p_{2}, p\right)+2\left\langle p-p_{2}, J p-J T^{n} p\right\rangle+\xi_{n} .
$$

Multiplying $t$ and $(1-t)$ on the both sides of (3.5) and (3.6), respectively, yields that

$$
\lim _{n \rightarrow \infty} \phi\left(p, T^{n} p\right)=0
$$

By Lemma 2.8, we see that $T^{n} p \rightarrow p$ as $n \rightarrow \infty$. Hence $T T^{n} p=T^{n+1} p \rightarrow p$ as $n \rightarrow \infty$. In view of the closedness of $T$, we can obtain that $p \in F(T)$. This shows that $F(T)$ is convex. In the way, we can obtain that $F(S)$ is also convex. This completes the proof that $\mathcal{F}$ is closed and convex.

Now, we show that $C_{n}$ is closed and convex for each $n \geq 1$. It is obvious that $C_{1}=C$ is closed and convex. Suppose that $C_{h}$ is closed and convex for some $h \in \mathbb{N}$. For $z \in C_{h}$, we see that

$$
\phi\left(z, y_{h}\right) \leq \phi\left(z, x_{h}\right)+\alpha_{h}\left(\left\|x_{1}\right\|^{2}+2\left\langle z, J x_{h}-J x_{1}\right\rangle\right)+\left(k_{h}-1\right) M_{h}+\xi_{h}
$$

is equivalent to

$$
2\left\langle z, J x_{h}-J y_{h}\right\rangle+2 \alpha_{h}\left\langle z, J x_{1}-J x_{h}\right\rangle \leq\left\|x_{h}\right\|^{2}-\left\|y_{h}\right\|^{2}+\alpha_{h}\left\|x_{1}\right\|^{2}+\left(k_{h}-1\right) M_{h}+\xi_{h} .
$$

It is not hard to see that $C_{h+1}$ is closed and convex. Then, for each $n \geq 1, C_{n}$ is closed and convex. This shows that $\Pi_{C_{n+1}} x_{1}$ is well defined.

Next, we prove that $\mathcal{F} \subset C_{n}$ for each $n \geq 1 . \mathcal{F} \subset C_{1}=C$ is obvious. Suppose that $\mathcal{F} \subset C_{h}$ for some $h \in \mathbb{N}$. Then, $\forall w \in \mathcal{F} \subset C_{h}$, we find from Lemma 2.7 that

$$
\begin{aligned}
\phi\left(w, z_{h}\right)= & \phi\left(w, J^{-1}\left(\beta_{h} J x_{h}+\gamma_{h} J T^{h} x_{h}+\delta_{h} J S^{h} x_{h}\right)\right) \\
= & \|w\|^{2}-2\left\langle w, \beta_{h} J x_{h}+\gamma_{h} J T^{h} x_{h}+\delta_{h} J S^{h} x_{h}\right\rangle+\left\|\beta_{h} J x_{h}+\gamma_{h} J T^{h} x_{h}+\delta_{h} J S^{h} x_{h}\right\|^{2} \\
\leq & \|w\|^{2}-2 \beta_{h}\left\langle w, J x_{h}\right\rangle-2 \gamma_{h}\left\langle w, J T^{h} x_{h}\right\rangle-2 \delta_{h}\left\langle w, J S^{h} x_{h}\right\rangle \\
& +\beta_{h}\left\|x_{h}\right\|^{2}+\gamma_{h}\left\|T^{h} x_{h}\right\|^{2}+\delta_{h}\left\|S^{h} x_{h}\right\|^{2} \\
= & \beta_{h} \phi\left(w, x_{h}\right)+\gamma_{h} \phi\left(w, T^{h} x_{h}\right)+\delta_{h} \phi\left(w, S^{h} x_{h}\right) \\
\leq & \beta_{h} \phi\left(w, x_{h}\right)+\gamma_{h} k_{h} \phi\left(w, x_{h}\right)+\gamma_{h} \xi_{h}+\delta_{h} k_{h} \phi\left(w, x_{h}\right)+\delta_{h} \xi_{h} \\
\leq & \phi\left(w, x_{h}\right)+\left(k_{h}-1\right) \phi\left(w, x_{h}\right)+\xi_{h} .
\end{aligned}
$$

It follows that

$$
\begin{aligned}
\phi\left(w, y_{h}\right) & =\phi\left(w, J^{-1}\left(\alpha_{h} J x_{1}+\left(1-\alpha_{h}\right) J z_{h}\right)\right) \\
& =\|w\|^{2}-2\left\langle w, \alpha_{h} J x_{1}+\left(1-\alpha_{h}\right) J T^{h} x_{h}\right\rangle+\left\|\alpha_{h} J x_{1}+\left(1-\alpha_{h}\right) J z_{h}\right\|^{2}
\end{aligned}
$$




$$
\begin{aligned}
& \leq\|w\|^{2}-2 \alpha_{h}\left\langle w, J x_{1}\right\rangle-2\left(1-\alpha_{h}\right)\left\langle w, J z_{h}\right\rangle+\alpha_{h}\left\|x_{1}\right\|^{2}+\left(1-\alpha_{h}\right)\left\|z_{h}\right\|^{2} \\
& =\alpha_{h} \phi\left(w, x_{1}\right)+\left(1-\alpha_{h}\right) \phi\left(w, z_{h}\right) \\
& \leq \alpha_{h} \phi\left(w, x_{1}\right)+\left(1-\alpha_{h}\right) \phi\left(w, x_{h}\right)+\left(k_{h}-1\right)\left(1-\alpha_{h}\right) \phi\left(w, x_{h}\right)+\xi_{h} \\
& \leq \phi\left(w, x_{h}\right)+\alpha_{h}\left(\phi\left(w, x_{1}\right)-\phi\left(w, x_{h}\right)\right)+\left(k_{h}-1\right)\left(1-\alpha_{h}\right) \phi\left(w, x_{h}\right)+\xi_{h} \\
& \leq \phi\left(w, x_{h}\right)+\alpha_{h}\left(\left\|x_{1}\right\|^{2}+2\left\langle w, J x_{h}-J x_{1}\right\rangle\right)+\left(k_{h}-1\right) M_{h}+\xi_{h} .
\end{aligned}
$$

This shows that $w \in C_{h+1}$. This implies that $\mathcal{F} \subset C_{n}$. In view of $x_{n}=\Pi_{C_{n}} x_{1}$, we see that

$$
\left\langle x_{n}-z, J x_{1}-J x_{n}\right\rangle \geq 0, \quad \forall z \in C_{n} .
$$

By $\mathcal{F} \subset C_{n}$, we find that

$$
\left\langle x_{n}-w, J x_{1}-J x_{n}\right\rangle \geq 0, \quad \forall w \in \mathcal{F}
$$

From Lemma 2.6, we see that

$$
\phi\left(x_{n}, x_{1}\right)=\phi\left(\Pi_{C_{n}} x_{1}, x_{1}\right) \leq \phi\left(w, x_{1}\right)-\phi\left(w, x_{n}\right) \leq \phi\left(w, x_{1}\right)
$$

for each $w \in \mathcal{F} \subset C_{n}$. Therefore, the sequence $\phi\left(x_{n}, x_{1}\right)$ is bounded. This implies that $\left\{x_{n}\right\}$ is bounded. On the other hand, in view of $x_{n}=\Pi_{C_{n}} x_{1}$ and $x_{n+1}=\Pi_{C_{n+1}} x_{1} \in C_{n+1} \subset C_{n}$, we have

$$
\phi\left(x_{n}, x_{1}\right) \leq \phi\left(x_{n+1}, x_{1}\right), \quad \forall n \geq 1
$$

Therefore, $\left\{\phi\left(x_{n}, x_{1}\right)\right\}$ is nondecreasing. It follows that the limit of $\left\{\phi\left(x_{n}, x_{1}\right)\right\}$ exists. By the construction of $C_{n}$, we have that $C_{m} \subset C_{n}$ and $x_{m}=\Pi_{C_{m}} x_{1} \in C_{n}$ for any positive integer $m \geq n$. It follows that

$$
\begin{aligned}
\phi\left(x_{m}, x_{n}\right) & =\phi\left(x_{m}, \Pi_{C_{n}} x_{1}\right) \\
& \leq \phi\left(x_{m}, x_{1}\right)-\phi\left(\Pi_{C_{n}} x_{1}, x_{1}\right) \\
& =\phi\left(x_{m}, x_{1}\right)-\phi\left(x_{n}, x_{1}\right) .
\end{aligned}
$$

Letting $m, n \rightarrow \infty$ in (3.8), we see that $\phi\left(x_{m}, x_{n}\right) \rightarrow 0$. It follows from Lemma 2.8 that $x_{m}-x_{n} \rightarrow 0$ as $m, n \rightarrow \infty$. Hence, $\left\{x_{n}\right\}$ is a Cauchy sequence. Since $E$ is a Banach space and $C$ is closed and convex, we can assume that

$$
\lim _{n \rightarrow \infty} x_{n}=p \in C
$$

Now, we are in a position to show $p \in F(T) \cap F(S)$. By taking $m=n+1$, we obtain that

$$
\lim _{n \rightarrow \infty} \phi\left(x_{n+1}, x_{n}\right)=0 .
$$

In view of Lemma 2.8, we see that

$$
\lim _{n \rightarrow \infty}\left\|x_{n+1}-x_{n}\right\|=0 .
$$


Since $x_{n+1} \in C_{n+1}$, we obtain that

$$
\phi\left(x_{n+1}, y_{n}\right) \leq \phi\left(x_{n+1}, x_{n}\right)+\alpha_{n}\left(\left\|x_{1}\right\|^{2}+2\left\langle z, J x_{n}-J x_{1}\right\rangle\right)+\left(k_{n}-1\right) M_{n}+\xi_{n} .
$$

In view of condition (b), we find from (3.10) that

$$
\lim _{n \rightarrow \infty} \phi\left(x_{n+1}, y_{n}\right)=0
$$

This in turn implies from Lemma 2.8 that

$$
\lim _{n \rightarrow \infty}\left\|x_{n+1}-y_{n}\right\|=0
$$

Note that

$$
\left\|x_{n}-y_{n}\right\| \leq\left\|x_{n}-x_{n+1}\right\|+\left\|x_{n+1}-y_{n}\right\|
$$

Combining (3.11) with (3.13) yields that

$$
\lim _{n \rightarrow \infty}\left\|x_{n}-y_{n}\right\|=0
$$

Since $J$ is uniformly norm-to-norm continuous on bounded sets, we have

$$
\lim _{n \rightarrow \infty}\left\|J x_{n}-J y_{n}\right\|=0
$$

On the other hand, we have $J y_{n}-J z_{n}=\alpha_{n}\left(J x_{1}-J z_{n}\right)$. In view of condition (a), we see that

$$
\lim _{n \rightarrow \infty}\left\|J y_{n}-J z_{n}\right\|=0
$$

Note that

$$
\left\|J x_{n}-J z_{n}\right\| \leq\left\|J x_{n}-J y_{n}\right\|+\left\|J y_{n}-J z_{n}\right\|
$$

Combining (3.15) with (3.16), we arrive at

$$
\lim _{n \rightarrow \infty}\left\|J x_{n}-J z_{n}\right\|=0
$$

Since $J^{-1}$ is also uniformly norm-to-norm continuous on bounded sets, we obtain that

$$
\lim _{n \rightarrow \infty}\left\|x_{n}-z_{n}\right\|=0
$$

Since $E$ is a uniformly smooth Banach space, we know that $E^{*}$ is a uniformly convex Banach space. Let $r=\sup _{n \geq 1}\left\{\left\|x_{n}\right\|,\left\|T^{n} x_{n}\right\|,\left\|S^{n} x_{n}\right\|\right\}$. From Lemma 2.8, we have

$$
\begin{aligned}
& \phi\left(w, z_{n}\right) \\
& \quad=\phi\left(w, J^{-1}\left(\beta_{n} J x_{n}+\gamma_{n} J T^{n} x_{n}+\delta_{n} J S^{n} x_{n}\right)\right)
\end{aligned}
$$




$$
\begin{aligned}
= & \|w\|^{2}-2\left\langle w, \beta_{n} J x_{n}+\gamma_{n} J T^{n} x_{n}+\delta_{n} J S^{n} x_{n}\right\rangle+\left\|\beta_{n} J x_{n}+\gamma_{n} J T^{n} x_{n}+\delta_{n} J S^{n} x_{n}\right\|^{2} \\
\leq & \|w\|^{2}-2 \beta_{n}\left\langle w, J x_{n}\right\rangle-2 \gamma_{n}\left\langle w, J T^{n} x_{n}\right\rangle-2 \delta_{n}\left\langle w, J S^{n} x_{n}\right\rangle \\
& +\beta_{n}\left\|x_{n}\right\|^{2}+\gamma_{n}\left\|T^{n} x_{n}\right\|^{2}+\delta_{n}\left\|S^{n} x_{n}\right\|^{2}-\gamma_{n} \delta_{n} g\left(\left\|J T^{n} x_{n}-J S^{n} x_{n}\right\|\right) \\
\leq & \beta_{n} \phi\left(w, x_{n}\right)+\gamma_{n} \phi\left(w, T^{n} x_{n}\right)+\delta_{n} \phi\left(w, S^{n} x_{n}\right)-\gamma_{n} \delta_{n} g\left(\left\|J T^{n} x_{n}-J S^{n} x_{n}\right\|\right) \\
\leq & \beta_{n} \phi\left(w, x_{n}\right)+\gamma_{n} k_{n} \phi\left(w, x_{n}\right)+\delta_{n} k_{n} \phi\left(w, x_{n}\right)-\gamma_{n} \delta_{n} g\left(\left\|J T^{n} x_{n}-J S^{n} x_{n}\right\|\right)+\xi_{n} \\
\leq & \phi\left(w, x_{n}\right)+\left(k_{n}-1\right) \phi\left(w, x_{n}\right)-\gamma_{n} \delta_{n} g\left(\left\|J T^{n} x_{n}-J S^{n} x_{n}\right\|\right)+\xi_{n} .
\end{aligned}
$$

It follows that

$$
\gamma_{n} \delta_{n} g\left(\left\|J T^{n} x_{n}-J S^{n} x_{n}\right\|\right) \leq \phi\left(w, x_{n}\right)-\phi\left(w, z_{n}\right)+\left(k_{n}-1\right) \phi\left(w, x_{n}\right)+\xi_{n} .
$$

On the other hand, we have

$$
\begin{aligned}
\phi\left(w, x_{n}\right)-\phi\left(w, z_{n}\right) & =\left\|x_{n}\right\|^{2}-\left\|z_{n}\right\|^{2}-2\left\langle w, J x_{n}-J z_{n}\right\rangle \\
& \leq\left\|x_{n}-z_{n}\right\|\left(\left\|x_{n}\right\|+\left\|z_{n}\right\|\right)+2\|w\|\left\|J x_{n}-J z_{n}\right\| .
\end{aligned}
$$

It follows from (3.17) and (3.18) that

$$
\phi\left(w, x_{n}\right)-\phi\left(w, z_{n}\right) \rightarrow 0 \quad \text { as } n \rightarrow \infty
$$

In view of the assumption $\liminf _{n \rightarrow \infty} \gamma_{n} \delta_{n}>0$, we find from (3.19) that

$$
\lim _{n \rightarrow \infty} g\left(\left\|J T^{n} x_{n}-J S^{n} x_{n}\right\|\right)=0
$$

It follows from the property of $g$ that

$$
\lim _{n \rightarrow \infty}\left\|J T^{n} x_{n}-J S^{n} x_{n}\right\|=0
$$

Since $J^{-1}$ is also uniformly norm-to-norm continuous on bounded sets, we arrive at

$$
\lim _{n \rightarrow \infty}\left\|T^{n} x_{n}-S^{n} x_{n}\right\|=0
$$

On the other hand, we have

$$
\begin{aligned}
\phi\left(T^{n} x_{n}, S^{n} x_{n}\right) & =\left\|T^{n} x_{n}\right\|^{2}-2\left\langle T^{n} x_{n}, J S^{n} x_{n}\right\rangle+\left\|S^{n} x_{n}\right\|^{2} \\
& =\left\|T^{n} x_{n}\right\|^{2}-2\left\langle T^{n} x_{n}, J T^{n} x_{n}\right\rangle+2\left\langle T^{n} x_{n}, J T^{n} x_{n}-J S^{n} x_{n}\right\rangle+\left\|S^{n} x_{n}\right\|^{2} \\
& \leq\left\|S^{n} x_{n}\right\|^{2}-\left\|T^{n} x_{n}\right\|^{2}+2\left\|T^{n} x_{n}\right\|\left\|J T^{n} x_{n}-J S^{n} x_{n}\right\| \\
& \leq\left(\left\|S^{n} x_{n}\right\|+\left\|T^{n} x_{n}\right\|\right)\left\|S^{n} x_{n}-T^{n} x_{n}\right\|+2\left\|T^{n} x_{n}\right\|\left\|J T^{n} x_{n}-J S^{n} x_{n}\right\| .
\end{aligned}
$$

From (3.21) and (3.22), we arrive at

$$
\lim _{n \rightarrow \infty} \phi\left(T^{n} x_{n}, S^{n} x_{n}\right)=0 .
$$


On the other hand, we have

$$
\begin{aligned}
\phi( & \left.T^{n} x_{n}, z_{n}\right) \\
= & \phi\left(T^{n} x_{n}, J^{-1}\left(\beta_{n} J x_{n}+\gamma_{n} J T^{n} x_{n}+\delta_{n} J S^{n} x_{n}\right)\right) \\
= & \left\|T^{n} x_{n}\right\|^{2}-2\left\langle T^{n} x_{n}, \beta_{n} J x_{n}+\gamma_{n} J T^{n} x_{n}+\delta_{n} J S^{n} x_{n}\right\rangle \\
& +\left\|\beta_{n} J x_{n}+\gamma_{n} J T^{n} x_{n}+\delta_{n} J S^{n} x_{n}\right\|^{2} \\
\leq & \left\|T^{n} x_{n}\right\|^{2}-2 \beta_{n}\left\langle T^{n} x_{n}, J x_{n}\right\rangle-2 \gamma_{n}\left\langle T^{n} x_{n}, J T^{n} x_{n}\right\rangle-2 \delta_{n}\left\langle T^{n} x_{n}, J S^{n} x_{n}\right\rangle \\
& +\beta_{n}\left\|x_{n}\right\|^{2}+\gamma_{n}\left\|T^{n} x_{n}\right\|^{2}+\delta_{n}\left\|S^{n} x_{n}\right\|^{2} \\
\leq & \beta_{n} \phi\left(T^{n} x_{n}, x_{n}\right)+\delta_{n} \phi\left(T^{n} x_{n}, S^{n} x_{n}\right) .
\end{aligned}
$$

In view of restriction (a), we find (3.23) that

$$
\lim _{n \rightarrow \infty} \phi\left(T^{n} x_{n}, z_{n}\right)=0 .
$$

It follows from Lemma 2.8 that

$$
\lim _{n \rightarrow \infty}\left\|T^{n} x_{n}-z_{n}\right\|=0 .
$$

Note that

$$
\left\|T^{n} x_{n}-p\right\| \leq\left\|T^{n} x_{n}-z_{n}\right\|+\left\|z_{n}-x_{n}\right\|+\left\|x_{n}-p\right\| .
$$

In view of (3.9), (3.18) and (3.25), we find that

$$
\lim _{n \rightarrow \infty}\left\|T^{n} x_{n}-p\right\|=0 .
$$

On the other hand, we have

$$
\left\|T^{n+1} x_{n}-p\right\| \leq\left\|T^{n+1} x_{n}-T^{n} x_{n}\right\|+\left\|T^{n} x_{n}-p\right\| .
$$

Since $T$ is asymptotically regular, we obtain that

$$
\lim _{n \rightarrow \infty}\left\|T^{n+1} x_{n}-p\right\|=0
$$

That is, $T T^{n} x_{n} \rightarrow p$ as $n \rightarrow \infty$. From the closedness of $T$, we see that $p \in F(T)$. In the same way, we can also obtain that $p \in F(S)$. This shows that $p \in \mathcal{F}$.

Finally, we show that $p=\Pi_{\mathcal{F} x_{1}}$. Taking the limit as $n \rightarrow \infty$ in (3.7), we obtain that

$$
\left\langle p-w, J x_{1}-J p\right\rangle \geq 0, \quad \forall w \in \mathcal{F},
$$

and hence $p=\Pi_{\mathcal{F} \mathcal{X}_{1}}$ by Lemma 2.5. This completes the proof.

Remark 3.2 Theorem 3.1 includes Theorem 2.4 in Section 2 as a special case. The framework of the space can be applicable to $L^{p}$, where $p \geq 1$. More precisely, $L^{p}$ is $\min \{p, 2\}$ uniformly smooth and uniformly convex for every $p \geq 1$.

In the framework of Hilbert spaces, we find the following. 
Corollary 3.3 Let E be a Hilbert space. Let $C$ be a nonempty closed and convex subset of E. Let $T: C \rightarrow C$ be a closed and generalized asymptotically quasi-nonexpansive mapping with a sequence $\left\{e_{n}\right\} \subset[1, \infty)$ such that $e_{n} \rightarrow 1$ as $n \rightarrow \infty$ and a sequence $\left\{\mu_{n}\right\} \subset[0, \infty)$, where $v_{n} \rightarrow 0$ as $n \rightarrow \infty$. Let $S: C \rightarrow C$ be a closed and generalized asymptotically quasinonexpansive mapping with a sequence $\left\{f_{n}\right\} \subset[1, \infty)$ such that $f_{n} \rightarrow 1$ as $n \rightarrow \infty$ and a sequence $\left\{v_{n}\right\} \subset[0, \infty)$, where $v_{n} \rightarrow 0$ as $n \rightarrow \infty$. Assume that $T$ and $S$ are asymptotically regular on $C$ and $\mathcal{F}=F(T) \cap F(S)$ is nonempty and bounded. Let $\left\{x_{n}\right\}$ be a sequence generated in the following manner:

$$
\left\{\begin{array}{l}
x_{0} \in E \quad \text { chosen arbitrarily, } \\
C_{1}=C, \\
x_{1}=P_{C_{1}} x_{0}, \\
z_{n}=\beta_{n} x_{n}+\gamma_{n} T^{n} x_{n}+\delta_{n} J S^{n} x_{n}, \\
y_{n}=\alpha_{n} x_{1}+\left(1-\alpha_{n}\right) z_{n}, \\
C_{n+1}=\left\{z \in C_{n}:\left\|z-y_{n}\right\|^{2} \leq\left\|z-x_{n}\right\|^{2}+\alpha_{n}\left(\left\|x_{1}\right\|^{2}+2\left\langle z, x_{n}-x_{1}\right\rangle\right)+\left(k_{n}-1\right) M_{n}+\xi_{n}\right\}, \\
x_{n+1}=P_{C_{n+1}} x_{1},
\end{array}\right.
$$

where $k_{n}=\max \left\{e_{n}, f_{n}\right\}, \xi_{n}=\max \left\{\mu_{n}, v_{n}\right\}, M_{n}=\sup \left\{\left\|z-x_{n}\right\|^{2}: z \in \mathcal{F}\right\}$ for each $n \geq 1$ and $\left\{\alpha_{n}\right\},\left\{\beta_{n}\right\},\left\{\gamma_{n}\right\}$ and $\left\{\delta_{n}\right\}$ are real sequences in $(0,1)$ such that

(a) $\beta_{n}+\gamma_{n}+\delta_{n}=1$;

(b) $\lim _{n \rightarrow \infty} \alpha_{n}=\lim _{n \rightarrow \infty} \beta_{n}=0$;

(c) $\liminf _{n \rightarrow \infty} \gamma_{n} \delta_{n}>0$.

Then the sequence $\left\{x_{n}\right\}$ converges strongly to $P_{\mathcal{F}} x_{1}$, where $P_{\mathcal{F}}$ is the metric projection from $C$ onto $\mathcal{F}$.

For the class of asymptotically quasi- $\phi$-nonexpansive mappings, we find from Theorem 3.1 the following.

Corollary 3.4 Let E be a uniformly convex and uniformly smooth Banach space. Let $C$ be a nonempty closed and convex subset of $E$. Let $T: C \rightarrow C$ be a closed and asymptotically quasi- $\phi$-nonexpansive mapping with a sequence $\left\{e_{n}\right\} \subset[1, \infty)$ such that $e_{n} \rightarrow 1$ as $n \rightarrow \infty$. Let $S: C \rightarrow C$ be a closed and asymptotically quasi- $\phi$-nonexpansive mapping with a sequence $\left\{f_{n}\right\} \subset[1, \infty)$ such that $f_{n} \rightarrow 1$ as $n \rightarrow \infty$. Assume that $T$ and $S$ are asymptotically regular on $C$ and $\mathcal{F}=F(T) \cap F(S)$ is nonempty and bounded. Let $\left\{x_{n}\right\}$ be a sequence generated in the following manner:

$$
\left\{\begin{array}{l}
x_{0} \in E \quad \text { chosen arbitrarily, } \\
C_{1}=C, \\
x_{1}=\Pi_{C_{1}} x_{0}, \\
z_{n}=J^{-1}\left(\beta_{n} J x_{n}+\gamma_{n} J T^{n} x_{n}+\delta_{n} J S^{n} x_{n}\right), \\
y_{n}=J^{-1}\left(\alpha_{n} J x_{1}+\left(1-\alpha_{n}\right) J z_{n}\right), \\
C_{n+1}=\left\{z \in C_{n}: \phi\left(z, y_{n}\right) \leq \phi\left(z, x_{n}\right)+\alpha_{n}\left(\left\|x_{1}\right\|^{2}+2\left\langle z, J x_{n}-J x_{1}\right\rangle\right)+\left(k_{n}-1\right) M_{n}\right\}, \\
x_{n+1}=\Pi_{C_{n+1}} x_{1},
\end{array}\right.
$$


where $k_{n}=\max \left\{e_{n}, f_{n}\right\}, M_{n}=\sup \left\{\phi\left(z, x_{n}\right): z \in \mathcal{F}\right\}$ for each $n \geq 1$ and $\left\{\alpha_{n}\right\},\left\{\beta_{n}\right\},\left\{\gamma_{n}\right\}$ and $\left\{\delta_{n}\right\}$ are real sequences in $(0,1)$ such that

(a) $\beta_{n}+\gamma_{n}+\delta_{n}=1$;

(b) $\lim _{n \rightarrow \infty} \alpha_{n}=\lim _{n \rightarrow \infty} \beta_{n}=0$;

(c) $\liminf _{n \rightarrow \infty} \gamma_{n} \delta_{n}>0$.

Then the sequence $\left\{x_{n}\right\}$ converges strongly to $\Pi_{\mathcal{F}} x_{1}$, where $\Pi_{\mathcal{F}}$ is the generalized projection from $C$ onto $\mathcal{F}$.

If both $T$ and $S$ are quasi- $\phi$-nonexpansive, we find from Theorem 3.1 the following.

Corollary 3.5 Let E be a uniformly convex and uniformly smooth Banach space. Let $C$ be a nonempty closed and convex subset of E. Let $T: C \rightarrow C$ be a closed quasi- $\phi$-nonexpansive mapping, and $S: C \rightarrow C$ be a closed quasi- $\phi$-nonexpansive mapping with a nonempty common fixed point set. Let $\left\{x_{n}\right\}$ be a sequence generated in the following manner:

$$
\left\{\begin{array}{l}
x_{0} \in E \quad \text { chosen arbitrarily, } \\
C_{1}=C \\
x_{1}=\Pi_{C_{1} x_{0}} \\
z_{n}=J^{-1}\left(\beta_{n} J x_{n}+\gamma_{n} J T x_{n}+\delta_{n} J S x_{n}\right) \\
y_{n}=J^{-1}\left(\alpha_{n} J x_{1}+\left(1-\alpha_{n}\right) J z_{n}\right) \\
C_{n+1}=\left\{z \in C_{n}: \phi\left(z, y_{n}\right) \leq \phi\left(z, x_{n}\right)+\alpha_{n}\left(\left\|x_{1}\right\|^{2}+2\left\langle z, J x_{n}-J x_{1}\right\rangle\right)\right\} \\
x_{n+1}=\Pi_{C_{n+1}} x_{1}
\end{array}\right.
$$

where $\left\{\alpha_{n}\right\},\left\{\beta_{n}\right\},\left\{\gamma_{n}\right\}$ and $\left\{\delta_{n}\right\}$ are real sequences in $(0,1)$ such that

(a) $\beta_{n}+\gamma_{n}+\delta_{n}=1$;

(b) $\lim _{n \rightarrow \infty} \alpha_{n}=\lim _{n \rightarrow \infty} \beta_{n}=0$;

(c) $\liminf _{n \rightarrow \infty} \gamma_{n} \delta_{n}>0$.

Then the sequence $\left\{x_{n}\right\}$ converges strongly to $\Pi_{\mathcal{F}} x_{1}$, where $\Pi_{\mathcal{F}}$ is the generalized projection from $C$ onto $\mathcal{F}$.

Putting $\beta_{n}=0$ and $T=S$, we find from Corollary 3.5 the following.

Corollary 3.6 Let E be a uniformly convex and uniformly smooth Banach space. Let $C$ be a nonempty closed and convex subset of $E$. Let $T: C \rightarrow C$ be a closed quasi- $\phi$-nonexpansive mapping with a nonempty fixed point set. Let $\left\{x_{n}\right\}$ be a sequence generated in the following manner:

$$
\left\{\begin{array}{l}
x_{0} \in E \quad \text { chosen arbitrarily, } \\
C_{1}=C \\
x_{1}=\Pi_{C_{1} x_{0}} \\
y_{n}=J^{-1}\left(\alpha_{n} J x_{1}+\left(1-\alpha_{n}\right) J T x_{n}\right) \\
C_{n+1}=\left\{z \in C_{n}: \phi\left(z, y_{n}\right) \leq \phi\left(z, x_{n}\right)+\alpha_{n}\left(\left\|x_{1}\right\|^{2}+2\left\langle z, J x_{n}-J x_{1}\right\rangle\right)\right\} \\
x_{n+1}=\Pi_{C_{n+1}} x_{1}
\end{array}\right.
$$


where $\left\{\alpha_{n}\right\}$ is a real sequence in $(0,1)$ such that $\lim _{n \rightarrow \infty} \alpha_{n}=0$. Then the sequence $\left\{x_{n}\right\}$ converges strongly to $\Pi_{\mathcal{F}} x_{1}$, where $\Pi_{F(T)}$ is the generalized projection from $C$ onto $F(T)$.

\section{Remark 3.7 Corollary 3.6 is a Banach version of Theorem 2.1 in Section 2. The sets of $Q_{n}$ are also relaxed.}

\section{Competing interests}

The authors declare that they have no competing interests.

\section{Authors' contributions}

Both authors contributed equally to this work. Both authors read and approved the final manuscript.

\section{Author details}

${ }^{1}$ School of Mathematics and Information Science, North China University of Water Resources and Electric Power,

Zhengzhou, 450011, China. ${ }^{2}$ College of Science, Hebei University of Engineering, Handan, Hebei 056038, China.

\section{Acknowledgements}

The authors are grateful to the editor and the three anonymous reviewers' suggestions which improved the contents of the article.

\section{Received: 23 June 2013 Accepted: 10 September 2013 Published: 08 Nov 2013}

\section{References}

1. Byrne, C: A unified treatment of some iterative algorithms in signal processing and image reconstruction. Inverse Probl. 20, 103-120 (2008)

2. Fattorini, HO: Infinite-Dimensional Optimization and Control Theory. Cambridge University Press, Cambridge (1999)

3. Shen, J, Pang, LP: An approximate bundle method for solving variational inequalities. Commun. Optim. Theory 1 , 1-18 (2012)

4. Abdel-Salam, HS, Al-Khaled, K: Variational iteration method for solving optimization problems. J. Math. Comput. Sci. 2, 1475-1497 (2012)

5. Cho, SY, Kang, SM: Approximation of common solutions of variational inequalities via strict pseudocontractions. Acta Math. Sci. 32, 1607-1618 (2012)

6. Noor, MA, Noor, Kl, Waseem, M: Decomposition method for solving system of linear equations. Eng. Math. Lett. 2, 31-41 (2013)

7. Dhage, BC, Jadhav, NS: Differential inequalities and comparison theorems for first order hybrid integro-differential equations. Adv. Inequal. Appl. 2, 61-80 (2013)

8. Aamir, KM, Abbas, M, Radenovic, S: A logarithmic time complexity algorithm for pattern searching using product-sum property. Comput. Math. Appl. 62, 2162-2168 (2011)

9. Osu, BO, Solomon, OU: A stochastic algorithm for the valuation of financial derivatives using the hyperbolic distributional variates. Math. Finance Lett. 1, 43-56 (2012)

10. Cho, SY, Kang, SM: Approximation of fixed points of pseudocontraction semigroups based on a viscosity iterative process. Appl. Math. Lett. 24, 224-228 (2011)

11. Luo, H, Wang, Y: Iterative approximation for the common solutions of a infinite variational inequality system for inverse-strongly accretive mappings. J. Math. Comput. Sci. 2, 1660-1670 (2012)

12. Cho, SY, Qin, X, Kang, SM: Iterative processes for common fixed points of two different families of mappings with applications. J. Glob. Optim. (2012). doi:10.1007/s10898-012-0017-y

13. Pineda, MD, Galperin, EA: MAPLE code for the gamma algorithm for global optimization of uncertain functions in economy and finance. Comput. Math. Appl. 59, 2951-2963 (2010)

14. Dhage, BC, Nashine, HK, Patil, VS: Common fixed points for some variants of weakly contraction mappings in partially ordered metric spaces. Adv. Fixed Point Theory 3, 29-48 (2013)

15. Qin, X, Cho, SY, Kang, SM: An extragradient-type method for generalized equilibrium problems involving strictly pseudocontractive mappings. J. Glob. Optim. 49, 679-693 (2011)

16. Wang, ZM, Lou, W: A new iterative algorithm of common solutions to quasi-variational inclusion and fixed point problems. J. Math. Comput. Sci. 3, 57-72 (2013)

17. Saluja, GS: Strong convergence theorems for two finite families of asymptotically quasi-nonexpansive type mappings in Banach spaces. Adv. Fixed Point Theory 3, 213-225 (2013)

18. Takahashi, W, Tsukiyama, N: Approximating fixed points of nonexpansive mappings with compact domains. Commun. Appl. Nonlinear Anal. 7, 39-47 (2000)

19. Kohsaka, F, Takahashi, W: Strongly convergent net given by a fixed point theorem for firmly nonexpansive type mappings. Appl. Math. Comput. 202, 760-765 (2008)

20. Cho, SY, Li, W, Kang, SM: Convergence analysis of an iterative algorithm for monotone operators. J. Inequal. Appl. 2013, 199 (2013)

21. Ye, J, Huang, J: Strong convergence theorems for fixed point problems and generalized equilibrium problems of three relatively quasi-nonexpansive mappings in Banach spaces. J. Math. Comput. Sci. 1, 1-18 (2011)

22. Qin, X, Chang, SS, Cho, YJ: Iterative methods for generalized equilibrium problems and fixed point problems with applications. Nonlinear Anal. 11, 2963-2972 (2010)

23. Goebel, K, Kirk, WA: A fixed point theorem for asymptotically nonexpansive mappings. Proc. Am. Math. Soc. 35 $171-174(1972)$ 
24. Halpern, B: Fixed points of nonexpanding maps. Bull. Am. Math. Soc. 73, 957-961 (1967)

25. $\mathrm{Wu}, \mathrm{CQ}, \mathrm{HaO}, \mathrm{Y}$ : Strong convergence of a modified Halpern-iteration for asymptotically quasi- $\boldsymbol{\phi}$-nonexpansive mappings. An. St. Univ. Ovidius Constanta 21, 261-276 (2013)

26. Cho, YJ, Qin, X, Kang, SM: Strong convergence of the modified Halpern-type iterative algorithms in Banach spaces. An. St. Univ. Ovidius Constanta 17, 51-68 (2009)

27. Martinez-Yanes, C, Xu, HK: Strong convergence of the CQ method for fixed point iteration processes. Nonlinear Anal. 64, 2400-2411 (2006)

28. Plubtieng, S, Ungchittrakool, K: Strong convergence theorems for a common fixed point of two relatively nonexpansive mappings in a Banach space. J. Approx. Theory 149, 103-115 (2007)

29. Qin, X, Cho, YJ, Kang, SM, Zhou, H: Convergence of a modified Halpern-type iteration algorithm for quasi- $\phi$-nonexpansive mappings. Appl. Math. Lett. 22, 1051-1055 (2009)

30. Su, Y, Wang, Z, Xu, H: Strong convergence theorems for a common fixed point of two hemi-relatively nonexpansive mappings. Nonlinear Anal. 71, 5616-5628 (2009)

31. Qin, $X$, Su, Y: Strong convergence theorem for relatively nonexpansive mappings in a Banach space. Nonlinear Anal. 67, 1958-1965 (2007)

32. Cioranescu, I: Geometry of Banach Spaces, Duality Mappings and Nonlinear Problems. Kluwer Academic, Dordrecht (1990)

33. Alber, Yl: Metric and generalized projection operators in Banach spaces: properties and applications. In: Kartsatos, AG (ed.) Theory and Applications of Nonlinear Operators of Accretive and Monotone Type. Dekker, New York (1996)

34. Agarwal, RP, Cho, YJ, Qin, X: Generalized projection algorithms for nonlinear operators. Numer. Funct. Anal. Optim. 28, 1197-1215 (2007)

35. Qin, X, Cho, YJ, Kang, SM: Convergence theorems of common elements for equilibrium problems and fixed point problems in Banach spaces. J. Comput. Appl. Math. 225, 20-30 (2009)

36. Zhou, H, Gao, G, Tan, B: Convergence theorems of a modified hybrid algorithm for a family of quasi- $\phi$-asymptotically nonexpansive mappings. J. Appl. Math. Comput. 32, 453-464 (2010)

37. Qin, X, Cho, SY, Kang, SM: On hybrid projection methods for asymptotically quasi- $\boldsymbol{\phi}$-nonexpansive mappings. Appl. Math. Comput. 215, 3874-3883 (2010)

38. Qin, X, Agarwal, RP, Cho, SY, Kang, SM: Convergence of algorithms for fixed points of generalized asymptotically quasi- $\phi$-nonexpansive mappings with applications. Fixed Point Theory Appl. 2012, 58 (2012)

39. Agarwal, RP, Qin, X, Kang, SM: An implicit iterative algorithm with errors for two families of generalized asymptotically nonexpansive mappings. Fixed Point Theory Appl. 2011, 58 (2011)

40. Shahzad, N, Zegeye, H: Strong convergence of an implicit iteration process for a finite family of generalized asymptotically quasi-nonexpansive maps. Appl. Math. Comput. 189, 1058-1065 (2007)

41. Lan, HY: Common fixed point iterative process with errors for generalized asymptotically quasi-nonexpansive mappings. Comput. Math. Appl. 52, 1403-1412 (2006)

42. Cho, YJ, Zhou, H, Guo, G: Weak and strong convergence theorems for three-step iterations with errors for asymptotically nonexpansive mappings. Comput. Math. Appl. 47, 707-717 (2004)

43. Kamimura, S, Takahashi, W: Strong convergence of a proximal-type algorithm in a Banach space. SIAM J. Optim. 13 938-945 (2002)

10.1186/1687-1812-2013-279

Cite this article as: Zhao and Ji: A strong convergence theorem for fixed points of generalized asymptotically quasi- $\phi$-nonexpansive mappings. Fixed Point Theory and Applications 2013, 2013:279

\section{Submit your manuscript to a SpringerOpen ${ }^{\circ}$ journal and benefit from:}

- Convenient online submission

- Rigorous peer review

- Immediate publication on acceptance

- Open access: articles freely available online

- High visibility within the field

- Retaining the copyright to your article 